\title{
Investigating vaterite phase stabilisation by a tetrazole molecule during calcium carbonate crystallization
}

\author{
Massimiliano Massi*, Mark I. Ogden*, Franca Jones*† \\ † corresponding author.E-mail:F.Jones@curtin.edu.au \\ *Curtin University, Department of Chemistry, GPO Box U1987 6845 Perth Western Australia. Fax: 6189266 4699; Tel: 618 \\ 92667677
}

\begin{abstract}
Tetrazole compounds have recently been found to impact on crystal morphology but in a manner different to carboxylate molecules. One such molecule was found to stabilize vaterite and this was investigated by assessing the impact of systematic changes on its structure. It was found that both the tetrazole and the acetyl functionality were required for vaterite stabilisation. The mechanism of stabilisation appears to be via inhibition of vaterite dissolution.
\end{abstract}

Keywords: A1. Biocrystallization, A1. Characterization, A1 Impurities, A1. Adsorption, A2. Growth from solutions, B1. Calcium compounds

\section{Introduction}

The impact of impurities or additives on crystal growth is relevant to many areas, including the control of scale formation, biomineralisation, pharmaceutical manufacturing, and so on [1-3]. From a fundamental perspective, additives have enabled the study of novel phenomena such as mesocrystal formation, by stabilising metastable crystalline structures $[4,5]$. In biomineralisation, minerals-associated proteins are proposed to be a key component of the exquisite control of crystal 
growth achieved in Nature; such proteins are typically rich in carboxylatefunctionalised amino acids (aspartic and glutamic acids). Industrial scale inhibitors, particularly polymeric additives, are also often carboxylate-based. Despite a very substantial body of literature, the fundamentals of additive-crystal surface interactions are still not fully understood, and the $a b$ initio prediction of the impact of a specific additive on a particular crystal system is yet to be achieved.

In this context, tetrazoles are an interesting functional group to consider. Tetrazoles and carboxylic acids have very similar pKa values, hence this heterocycle has often been employed as a more metabolically stable substituent replacing the carboxylic acid group. The replacement of the acid for the tetrazole has led to the discovery of a variety of formulations possessing medicinally relevant properties, viz. antifungal, antibacterial, anticancer and also antineurodegenerative activities [6].

The use of tetrazoles as non-metabolised analogues of carboxylates inspired us to investigate and compare their properties on crystal growth with respect to their carboxylic acids counterparts. We have previously reported that differently substituted 5-aryltetrazole species have an impact on $\mathrm{CaCO}_{3}$ and $\mathrm{BaSO}_{4}$ growth [7]. It was found that the impact of the tetrazole-functionalised additive is different to that of the equivalent carboxylate-containing molecule. In the case of $\mathrm{CaCO}_{3}$ crystal growth, one of the tetrazole-containing species, namely 4-(1H-tetrazol-5yl)benzaldehyde (herein referred to as 2 , Fig 1.) was found to stabilise vaterite particles, these being the dominant form even after 2 weeks incubation. This was not observed for other para functionalised aryltetrazoles investigated, viz. methyl 
4-(1H-tetrazol-5-yl)benzoate, (1H-tetrazol-5-yl)benzene and 1,4-bis(1H-tetrazol-5yl)benzene [7]. Vaterite stabilisation is of great interest in the field of Biomineralisation and in understanding the various mechanisms by which organic molecules can impact on crystallization (see [8] and references therein).

Stabilisation of vaterite is not commonly observed for small molecules although amino acids and ethylene glycol have been reported to do so [9, 10]. Inorganic ions, such as copper and magnesium ions, have been shown to form surface precipitates that stabilise vaterite by protecting it from dissolution $[11,12]$. For the most part, long term stabilisation of vaterite is achieved by the use of long chain organic molecules [13-15].

In this paper, therefore, we investigate what aspect of the functional group and its structure impacts on the ability of the molecule to stabilise or destabilise vaterite formation and probe the most likely mode in which the additive is stabilising the vaterite. In order to do this we compare the formyl/tetrazole 2 to the analogous carboxylate $\mathbf{1}$ and to the tetrazole/methyl ketone $\mathbf{3}$ (Figure 1).

Figure 1 near here

\section{Experimental}




\section{Synthesis}

Solvents and reagents, including the carboxylic acid 1, were purchased from Sigma Aldrich and used as received without any purification. Compounds $\mathbf{2}$ and $\mathbf{3}$ were synthesised according to a previously published procedure [16].

\section{Calcium Carbonate Crystal Growth by Diffusion}

Calcium carbonate crystals were grown slowly in the presence of additives, by diffusion of carbon dioxide and ammonia into a calcium chloride solution, as described previously [7]. Four open beakers containing calcium chloride solutions $(10 \mathrm{~mL}, 7 \mathrm{mmol})$ and the appropriate concentrations of the additives were placed in a glass desiccator (14 $\mathrm{cm}$ diameter, $7 \mathrm{~cm}$ deep). In order to facilitate the recovery of the crystals, microscope coverslips (pre-soaked in $1 \mathrm{M} \mathrm{HCl}$ and rinsed with ultrapure water and dried) were placed in the beakers. A vial of solid ammonium carbonate (ca. 1g) with a plastic screw cap punctured by a single needle hole was placed in the middle of the desiccator. The glass desiccator was then sealed. The coverslips were recovered at different times, up to a period of 2 weeks, or the time as stated, rinsed with water and dried in air before being prepared for SEM investigation. Additive solutions were added as $\mathrm{pH} 6$ adjusted solutions. In this system crystallization occurs as soon as the carbonate concentration is above the metastable limit and so is quite low in comparison the the supersaturation for the direct crystallization discussed below.

\section{Direct crystallization}


For the Raman and infrared analysis, calcium carbonate was also directly crystallized. This allowed the behaviour of the organic additives to be investigated in the absence of ammonia, which is known to have a small stabilising effect on vaterite [14]. In a clean glass beaker, $1 \mathrm{~mL}$ calcium chloride solution $(0.1 \mathrm{M})$ was diluted by the addition of $25 \mathrm{~mL}$ of ultrapure water. A magnetic stirrer bar was added and the solution stirred while $6 \mathrm{~mL}$ sodium carbonate $(0.1 \mathrm{M})$ was added drop wise. Excess carbonate was added so that the $\mathrm{pH}$ was raised sufficiently for crystallization. The formed solids were filtered immediately, washed three times with ultrapure water and dried in a dessicator at room temperature. The final supersaturation ratio for this reaction is very high and is calculated to be $\sim 19,500$. This was repeated with $1 \mathrm{~mL}(10,000 \mathrm{ppm})$ additive stock solution present. The dried solids were then ready for vibrational spectroscopy analysis.

\section{Vibrational Spectroscopy Analysis}

Raman spectroscopy is a relatively simple method of determining the polymorph of calcium carbonate present [17]. The cover slips were collected from the crystallization vials, excess fluid soaked up by tissue before being dried and stored in a desiccator. The dried coverslip was then viewed under a 50x microscope objective attched to a Dilor Labram 1B Raman spectrometer. A particle was chosen and the beam aligned with the centre of the particle before collecting data on that particle. The acquisition parameters for the Raman spectrum were: wavenumber region 100-1200 $\mathrm{cm}^{-1}, 4 \mathrm{~cm}^{-1}$ resolution, 1800 grating, using $633 \mathrm{~nm}$ laser reference beam. Similarly, the solids from the direct crystallization were viewed under a 50x microscope objective attached to the Dilor Labram 1B Raman spectrometer. The Raman spectrum was obtained using the same acquisition parameters stated above. 
In this instance however, discreet particles were not observed as they were too small (much less than $50 \mu \mathrm{m}$ ) and many particles are in the measurement zone. However, the Raman spectra from the slow diffusion experiments confirm the ability to differentiate between vaterite and calcite by this method.

Diffuse Reflectance Infrared Fourier Transform (DRIFT) was performed on the solids to determine the surface adsorbed organic species if present as this technique is more sensitive to surface adsorbed species [18]. The solids were diluted to $3 \mathrm{wt} \%$ in dry $\mathrm{KBr}$ and placed in a diffuse reflectance cup for the infrared spectrum collection. A diffuse reflectance accessory on a Bruker IFS 66 instrument with 4 $\mathrm{cm}^{-1}$ resolution and 256 scans per spectrum was run with pure $\mathrm{KBr}$ as the background.

\section{Scanning electron microscopy (SEM)}

The cover slips were collected from the crystallization vials, placed on a carbon coated SEM stub and carbon paint was applied to the edges of the glass cover slip to minimise charging effects before being stored in a desiccator. The samples were subsequently gold sputtered prior to viewing in a Philips XL30 or Zeiss Evo SEM.

\section{Turbidimetric analysis of nucleation rate}

The homogenous nucleation rate can be measured by nephelometry. In essence, the measurement of absorbance at $900 \mathrm{~nm}$ can be interpreted as a turbidity value [19] and the time taken before the turbidity increases above the background (known as the induction time) measured. Since the induction time is inversely proportional to the nucleation rate, changes in induction time directly relate to bulk/homogenous 
nucleation and the surface free energy of the critical nuclei [20]. The experimental conditions were similar to that for the direct precipitation. More specifically, $20 \mu \mathrm{L}$ of $0.1 \mathrm{M}$ calcium chloride solution was added to $4 \mathrm{~mL}$ ultrapure water in a UV cuvette. To initiate crystallization $120 \mu \mathrm{L}, 0.1 \mathrm{M}$ sodium carbonate solution (conditions mimic direct crystallization experiments) was added to the solution and the UV-vis data collection (absorbance versus time at $900 \mathrm{~nm}$ ) started. The benzyl additives were added to the volume of water such that $500 \mathrm{ppm}$ of additive was present and the volume was kept constant at $4 \mathrm{~mL}$.

\section{Results and Discussion}

\section{Slow Diffusion Morphologies and Phases}

The formyl and acetyl substituted 5-aryltetrazoles $\mathbf{2}$ and $\mathbf{3}$ were synthesised by treatment of the corresponding para substituted nitriles and sodium azide in the presence of triethylammonium chloride in refluxing toluene [16]. The crystallization of calcium carbonate in the absence of impurities is shown in Figure 2. Initially both calcite rhombs and vaterite spheres are observed and this was confirmed with the Raman spectrum from each of the different shaped particles (Figure 3). Raman spectroscopy was used throughout to confirm the composition of crystals of specific morphologies [17].

Calcium carbonate crystallization in the presence of the para-formyl benzoic acid 1 showed similar behaviour to the control, with the initially deposited vaterite transforming over time to calcite (lower magnification images can be found in the supplementary section). There does, however, appear to be more calcite present than in the control at a similar time (compare Figure $2 \mathrm{a}, \mathrm{b}$ and $\mathrm{c}$ ). 
Figure 2 near here

When tetrazole 2 is present during calcium carbonate crystallization we find no detectable calcite present with only vaterite observed. The vaterite persists even after 14 days in a form that shows no signs of dissolution. Despite the fact that ammonia stabilises vaterite somewhat, in the control experiment after 14 days the vaterite has converted to calcite, thus the impact we observe here is not due to ammonia stabilisation. In addition, we can conclude that exchanging the tetrazole moiety for the carboxylate group on the benzene ring has a significant impact on the crystal growth modification behaviour.

Next, retaining the tetrazole group in $\mathbf{2}$, and altering the formyl functionality was investigated using additive 3 . The resulting crystals are shown in Figure $2 \mathrm{~d}$; a mixture of vaterite and calcite is once again observed, as found for the blank and additive $\mathbf{1}$. The density of crystals deposited appears to be somewhat reduced, but this may have been a localised effect. Of most importance here, the results show that both the tetrazole and formyl groups are required to stabilise the vaterite crystals.

Figure 3 near here

Looking more closely at the particles formed to gain greater insight into the crystallization impacts, it is found that the calcite particles deposited in the presence of 1 have slightly curved edges compared to the control (Fig. 4a and b). This 
suggests that the additive has an inhibitory effect on the calcite crystal growth, resulting in inhibition at steps on the crystal face, as is observed for many carboxylate-based, and other, inhibitors [21, 22].

Figure 4 near here

The residual vaterite particles in the control diffusion experiment, on the other hand, show clear signs of dissolution especially when compared to that in the presence of species $\mathbf{2}$ (Fig. 5).

\section{Figure 5 near here}

Crystal growth in the presence of $\mathbf{3}$ results in similar behaviour to that observed for additive 1, including the impact on the calcite particles (i.e. causing rounded edges on the rhombs, Fig. 4c). Thus, the effect of $\mathbf{1}$ and $\mathbf{3}$ appears to be almost identical at this concentration. This is despite the many differences these two molecules have (c/f carboxylate versus tetrazole functionality and aldehyde versus ketone functionality).

The presence of $\mathbf{2}$ during crystallization results in vaterite crystallisation with the same morphology as observed in the blank. This suggests that the impact of this molecule is not on the growth of the vaterite as this would have induced some morphological change. Its dominant effect could be to halt the dissolution of the vaterite. The hypothesis that dissolution is inhibited is supported by the observation that even at 14 days little vaterite dissolution is observable in the SEM images (see 
Fig. 5b and Supplementary information SFig. 2).

\section{Turbidimetric analysis}

The results from the turbidity measurements (Figure 6a) show that while there is some scatter in the induction time measured for the calcium carbonate control, the fact that no particles are detected by 1000 seconds in the presence of all three additives at $500 \mathrm{ppm}$ (Figure 6b) implies that all three species inhibit homogenous nucleation (of vaterite) at this concentration. Thus, why one should promote vaterite over calcite crystallization is not elucidated by this behaviour as all three impact on the surface free energy in the same way.

Figure 6 near here

Also, it is interesting to note that the previous literature on the stabilization of vaterite by amino acids [10c] has shown that, generally, they lower the surface free energy of nucleation (meaning that a shortened induction time should have been observed). This is not observed for any of the species investigated in this work.

\section{DRIFT and Raman analysis}

In order to try and obtain information into the possible mechanism of this stabilisation, we also carried out direct crystallization experiments. These experiments are conducted in the absence of ammonia and thus any impact of ammonia can be excluded. In addition, it was important to determine whether the impact of the formyl tetrazole was to stabilise vaterite under quite different conditions. These experiments have a much shorter timeframe than the slow growth 
experiments discussed above and the supersaturation is also much higher.

It was found, using Raman spectral analysis, that only vaterite was observed when 2 was present (Figure 7). Thus, when 2 is not present, the vaterite is able to tranform to calcite even on this short timeframe (2-5 minutes). In fact, the control gave a mixture of calcite and vaterite as would be expected while for the case of the species 1 and $\mathbf{3}$ being present only calcite was observed in the Raman spectrum. Thus, as found for the SEM images, these latter two molecules appear to favour calcite formation.

Figure 7 near here

Thus, the results of both crystallization methods show the presence of $\mathbf{2}$ stabilises vaterite formation, and this stabilisation occurs under a variety of supersaturation conditions and in the absence of ammonia.

If we hypothesise that the stabilisation by species 2 is due to inhibition of the dissolution of vaterite then the mechanism must involve species 2 adsorbing onto the vaterite surface. We did not measure the calcium concentration in solution since, if the vaterite is being physically stopped from dissolving, it will not alter the thermodynamic equilibrium solubility of the system prior to the formation of the vaterite. Also, the morphology of the vaterite did not appear to be influenced by these molecules, thus, templating effects could be ruled out. The lack of morphological change suggests that species $\mathbf{2}$ may be a weak inhibitor affecting at most the rate of vaterite growth rather than the thermodynamics of the individual 
faces. Thus, we conducted DRIFT analysis to ascertain the molecules' respective adsorption onto the directly crystallized solids. DRIFT spectra on these samples clearly show that $\mathbf{2}$ is adsorbed on the surface of the calcium carbonate particles (see Fig. 8) but that the other molecules do not appear to be appreciably adsorbed. This is consistent with the impact of the additives $\mathbf{1}$ and $\mathbf{3}$ on calcium carbonate crystallization as threshold inhibitors (impacting on growth features only, for example).

Figure 8 near here

\section{Conclusions}

In this work we have demonstrated that the stabilisation of vaterite is possible using a small organic molecule. It is interesting to note that the previously reported amino acid vaterite stabilizers [10c] tended to promote vaterite nucleation while the all of the species in this work inhibit nucleation of vaterite.

In general, this work highlights the sensitivity of the crystallization of calcium carbonate to the organic molecules themselves. Not only is the tetrazole group necessary in order to observe the vaterite stabilisation behaviour but as we have shown here, so too is the aldehyde functional group. Conversion of this group to a ketone results in loss of vaterite stabilisation capacity. Both the acetylphenyl tetrazole (3) and the p-formylbenzoic acid (1) appear to have a calcite inducing effect. 
All three additives were found to inihibit homogenous nucleation. The mechanism of vaterite stabilisation, therefore, appears to be due to the greater adsorption of the tetrazole after formation of the vaterite and this adsorption impedes its dissolution, thereby hindering any transformation to calcite. While this is sometimes used to explain the impact of large protein molecules on vaterite stabilisation [23, 24], templating effects tend to be cited more often [25-30]. Our hypothesis, however, is supported by both the visual appearance of the vaterite after 14 days in the presence of the tetrazole and by the adsorption of the tetrazole onto the vaterite surface from DRIFT analysis. Also, the similarity in the inhibition of homogenous nucleation would suggest that species $\mathbf{2}$ should then behave (from a surface energy perspective) similarly to species $\mathbf{1}$ and $\mathbf{3}$. This was not observed. It suggests that in Nature, and just as is found for inorganic molecules, one way to stabilise vaterite is to limit its dissolution and therefore its transformation to calcite (which is known to occur via a dissolution-recrystallization step) [31].

Future work will focus on obtaining AFM data in the presence of these molecules and further investigating the role of chain length.

\section{Acknowledgements}

MM wishes to thank the ARC for the APD Fellowship (DP0985481), which partly supported this work.

Electronic Supplementary Information (ESI) available: Further SEM images of calcium carbonate particles, infrared spectrum of neat species 2 . 


\section{References}

1. F. Jones and M. I. Ogden, CrystEngComm, 12 (2010) 1016-1023.

2. S. Mann, Biomineralization: Principles and Concepts in Bioinorganic Materials Chemistry, Oxford University Press, Oxford, 2001.

3. N. Rodriguez-Hornedo and D. Murphy, J. Pharm. Sci., 88 (1999) 651-660.

4. H. Cölfen and M. Antonietti, Mesocrystals and Non Classical Crystallization, John Wiley \& Sons, Chichester, 2008.

5. M. Niederberger and H. Cölfen, Phys. Chem. Chem. Phys., 8 (2006) 3271-3287.

6. R. J. Herr, Biorg. Med. Chem., 10 (2002) 3379-3393.

7. M. Massi, M. I. Ogden, T. Radomirovic and F. Jones, CrystEngComm, 12 (2010) 4205-4207.

8. N. Spann, E. M. Harper, D. C. Aldridge, Naturwissenschaften, 97 (2010) 743 751.

9. E. M. Flaten, M. Seiersten and J. P. Andreassen, J. Cryst. Growth, 311 (2009) 3533-3538.

10. (a) A. Kai, K. Fujikawa and T. Miki, Jpn. J. Appl. Phys., Part 1, 41 (2002) 439444. (b) Malkaj, P.; Dalas, E., Cryst. Growth Des., 4 (2004) 721-723. (c) Manoli, F.; Dalas, E., J. Cryst. Growth, 222 (2001) 293-297.

11. N. Nassrallah-Aboukais, A. Boughriet, L. Gengembre and A. Aboukais, J. Chem. Soc., Faraday Trans., 94 (1998) 2399-2405.

12. N. Nassrallah-Aboukais, A. Boughriet, J. Laureyns, L. Gengembre and A. Aboukais, Chem. Mater., 11 (1999) 44-51.

13. M. Fricke, D. Volkmer, C. E. Krill III, M. Kellermann and A. Hirsch, Cryst. Growth Des., 6 (2006) 1120-1123. 
14. N. Gehrke, H. Colfen, N. Pinna, M. Antonietti and N. Nassif, Cryst. Growth Des., 5 (2005) 1317-1319.

15. J. Rudloff, M. Antonietti, H. Cölfen, J. Pretula, K. Kaluzynski and S. Penczek, Macromol. Chem. Phys., 203 (2002) 627-635.

16. K. Koguro, T. Oga, S. Mitsui and R. Orita, Synthesis-Stuttgart, (1998) 910-914.

17. A. Dandeu, B. Humbert, C. Carteret, H. Muhr, E. Plasari and J. M. Bossoutrot, Chem. Eng. Technol., 29 (2006) 221-225.

18. W. Qi Gong, A. Parentich, L. H. Little, L. J. Warren, Langmuir, 8 (1992) 118124.

19. K. C. Yang, R. Hogg, Analytical Chemistry, 51(6) (1979) 758-763.

20. J. W. Mullin (1961), Nucleation. In Crystallization, 3rd ed.; ButterworthHeinemann: Oxford, pp 172-201.

21 A. Baynton, B. D. Chandler, F. Jones, G. Nealon, M. I. Ogden, T. Radomirovic, G. K. H. Shimizu and J. M. Taylor, CrystEngComm, 13 (2011) 1090-1095.

22. J. J. De Yoreo and P. M. Dove, Science, 306 (2004) 1301-1302.

23. R. Lakshminarayanan, E. O. Chi-Jin, X. J. Loh, R. M. Kini and S. Valiyaveettil, Biomacromolecules, 6 (2005) 1429-1437.

24. X. Q. Wang, R. Kong, X. X. Pan, H. Xu, D. H. Xia, H. H. Shan and J. R. Lu, J. Phys. Chem. B, 113 (2009) 8975-8982.

25. S. R. Dickinson and K. M. McGrath, Cryst. Growth Des., 4 (2004) 1411-1418.

26. A. Kotachi, T. Miura and H. Imai, Cryst. Growth Des., 6 (2006) 1636-1641.

27. R. Lakshminarayanan, S. Vivekanandan, R. P. Samy, Y. Banerjee, E. O. ChiJin, K. W. Teo, S. D. S. Jois, R. M. Kini and S. Valiyaveettil, J. Am. Chem. Soc., 130 (2008) 4660-4668.

28. N. Loges, K. Graf, L. Nasdala and W. Tremel, Langmuir, 22 (2006) 3073-3080. 
29. T. Menahem and Y. Mastai, J. Cryst. Growth, 310 (2008) 3552-3556.

30. H. Colfen and L. M. Qi, Chem. Eur. J., 7 (2001) 106-116.

31. J. Rieger, T. Frechen, G. Cox, W. Heckmann, C. Schmidt and J. Thieme, Faraday Discuss., 136 (2007) 265-277. 
Figure captions

Figure 1. Carboxylic acid and tetrazole species used in this work as crystal growth modifiers.

Figure 2. SEM images of calcium carbonate formed after 7 days in the presence of a) no additives and 250ppm of b) species $\mathbf{1}$ c) species $\mathbf{2}$ and d) species $\mathbf{3}$

Figure 3. Raman spectra of vaterite and calcite particles from the control diffusion experiment. Raman spectrum from a calcite rhomb (singlet at $1083 \mathrm{~cm}^{-1}$ and $151 \mathrm{~cm}^{-1}$ are diagnostic of calcite) and vaterite flower (doublet at 1090 and 1074 $\mathrm{cm}^{-1}$ and broader peak at $\sim 110 \mathrm{~cm}^{-1}$ diagnostic of vaterite)

Figure 4. SEM images of calcite crystals after 7 days at (a) 0 and (b) with 250 ppm of species 1 present and (c) with 250 ppm species 3 present (all scale bars $20 \mu \mathrm{m})$

Figure 5. SEM images of vaterite flowers after 7 days at (a) 0 and with $250 \mathrm{ppm}$ of species (b) 1 present and (c) 2 present and (d) 3 present (scale bars $20 \mu \mathrm{m}$ for b and $10 \mu \mathrm{m}$ otherwise)

Figure 6. Absorbance at $900 \mathrm{~nm}$ versus time (a) reproducbility of method; greyed box shows variation in induction time measured (varied from $150-250 \mathrm{sec}$ ) in the presence of no additives and (b) with $500 \mathrm{ppm}$ of species $\mathbf{1}, \mathbf{2}$ and $\mathbf{3}$ present 
Figure 7. a) Raman spectra of calcium carbonate crystallized in the absence and presence of the additives. The $1080-1100 \mathrm{~cm}^{-1}$ region is shown in more detail in b) where the presence of calcite can be confirmed for the control and when additives $\mathbf{1}$ and $\mathbf{3}$ are present while vaterite is present in the control and in the presence of $\mathbf{2}$.

Figure 8. DRIFT spectra of calcium carbonate directly precipitated with and without additives present is shown. Differences in spectrum are highlighted by the rectangles when $\mathbf{2}$ is present. These peaks are from the tetrazole species (2) as confirmed by the solid state spectrum of $\mathbf{2}$ shown in the supplementary section (SFig. 3). 


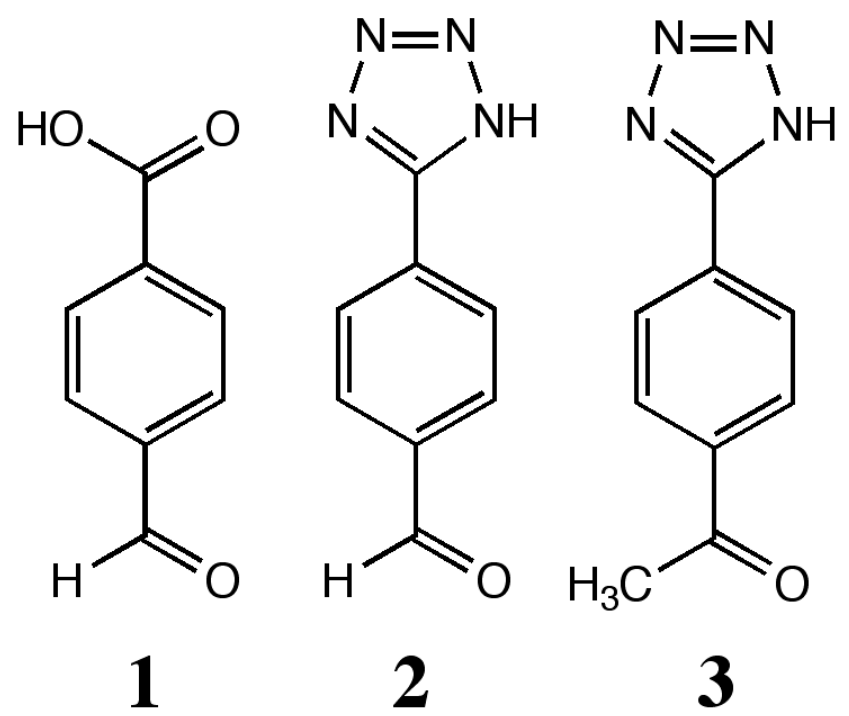

Figure 1. Carboxylic acid and tetrazole species used in this work as crystal growth modifiers.
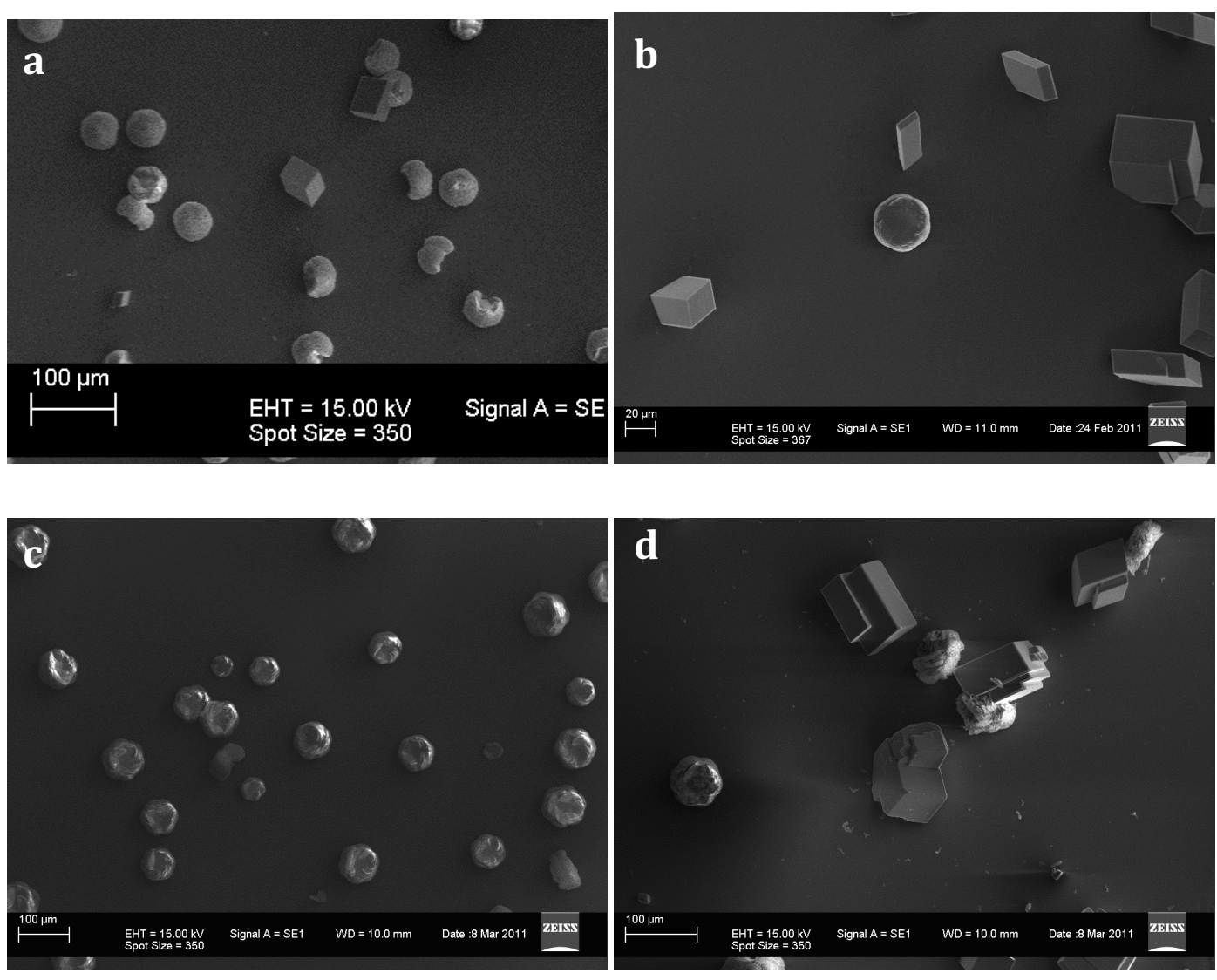

Figure 2. SEM images of calcium carbonate formed after 7 days in the presence of a) no additives and 250ppm b) species $1 \mathrm{c}$ ) species $\mathbf{2}$ d) species 3 

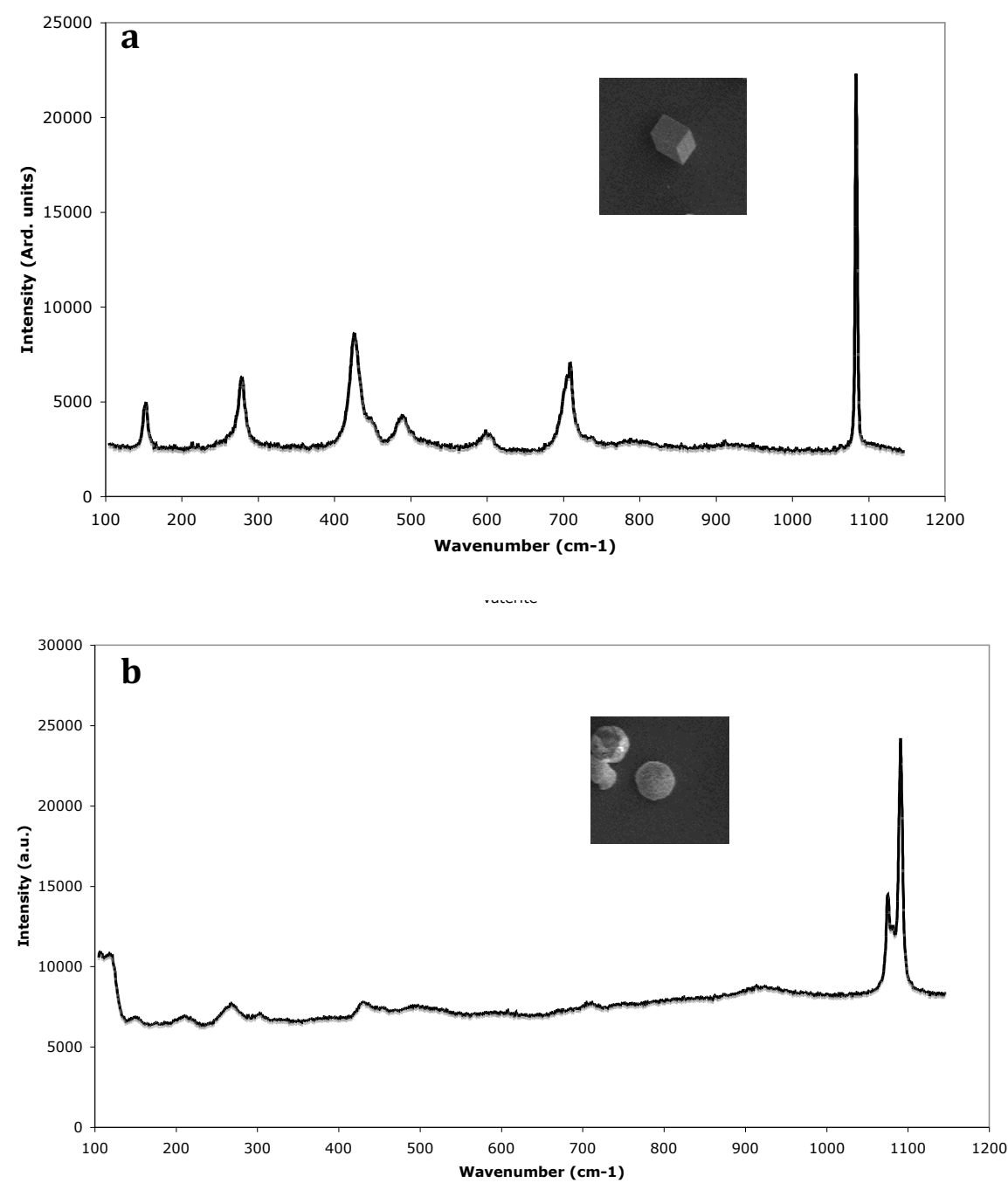

Figure 3. Raman spectra of vaterite and calcite particles from the control diffusion experiment. Raman spectrum from a calcite rhomb (singlet at $1083 \mathrm{~cm}^{-1}$ and $151 \mathrm{~cm}^{-1}$ are diagnostic of calcite) and vaterite flower (doublet at 1090 and 1074 $\mathrm{cm}^{-1}$ and broader peak at $\sim 110 \mathrm{~cm}^{-1}$ diagnostic of vaterite)
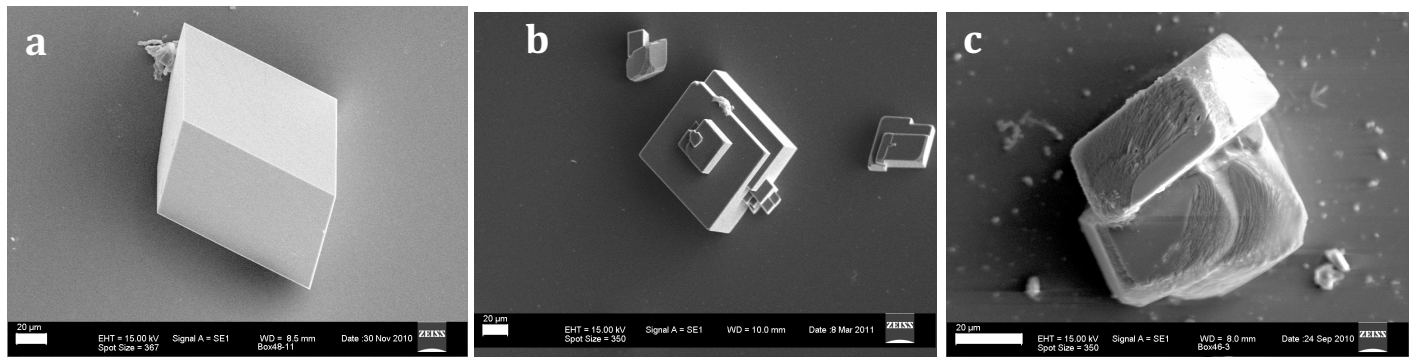

Figure 4. SEM images of calcite crystals after 7 days at (a) 0 and (b) with $250 \mathrm{ppm}$ of species $\mathbf{1}$ present and (c) with $250 \mathrm{ppm}$ species 3 present (all scale bars $20 \mu \mathrm{m}$ ) 

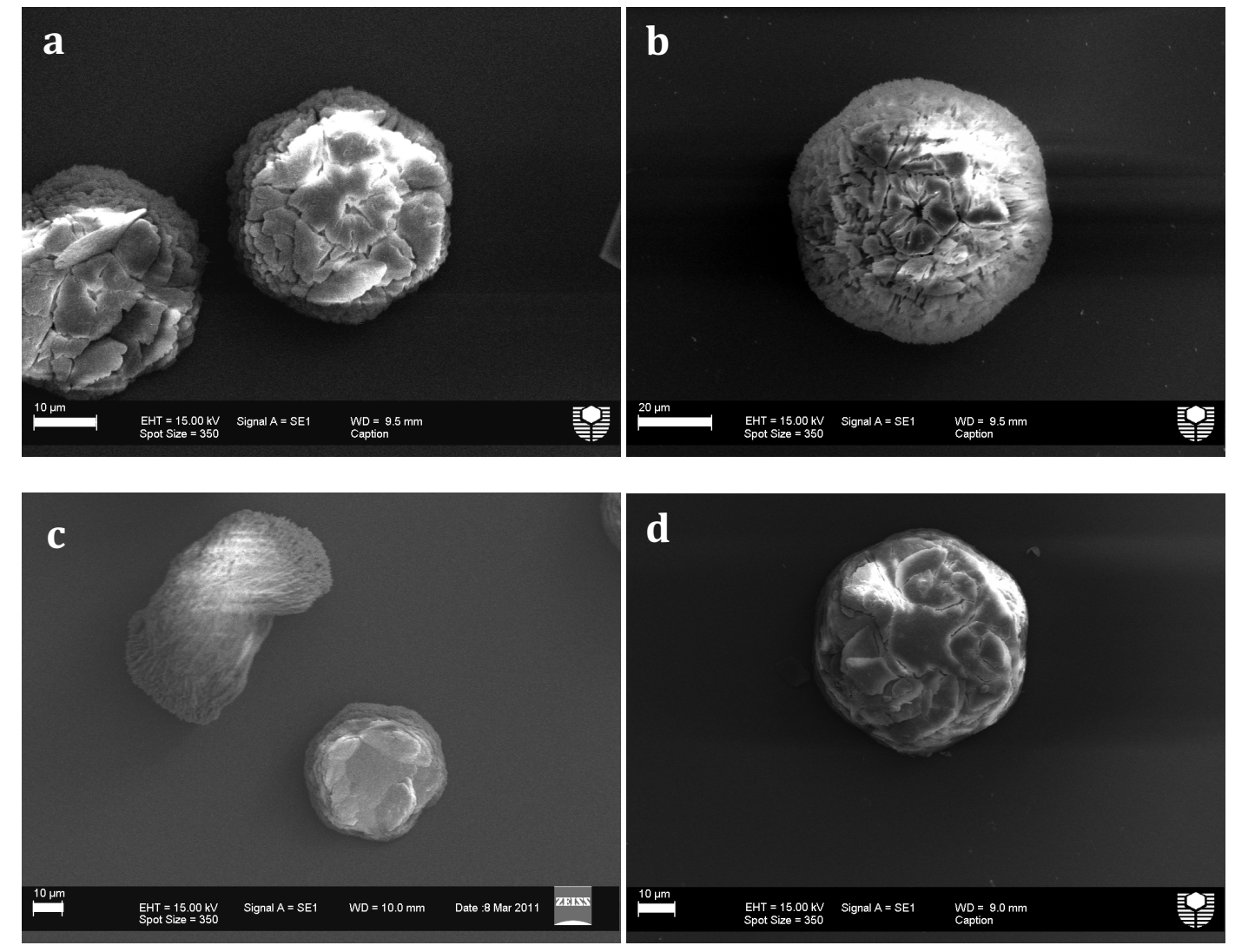

Figure 5. SEM images of vaterite flowers after 7 days at (a) 0 and with $250 \mathrm{ppm}$ of species (b) 1 present (c) 2 present and (d) 3 present (scale bars $20 \mu \mathrm{m}$ for $\mathrm{b}$ and $10 \mu \mathrm{m}$ otherwise)
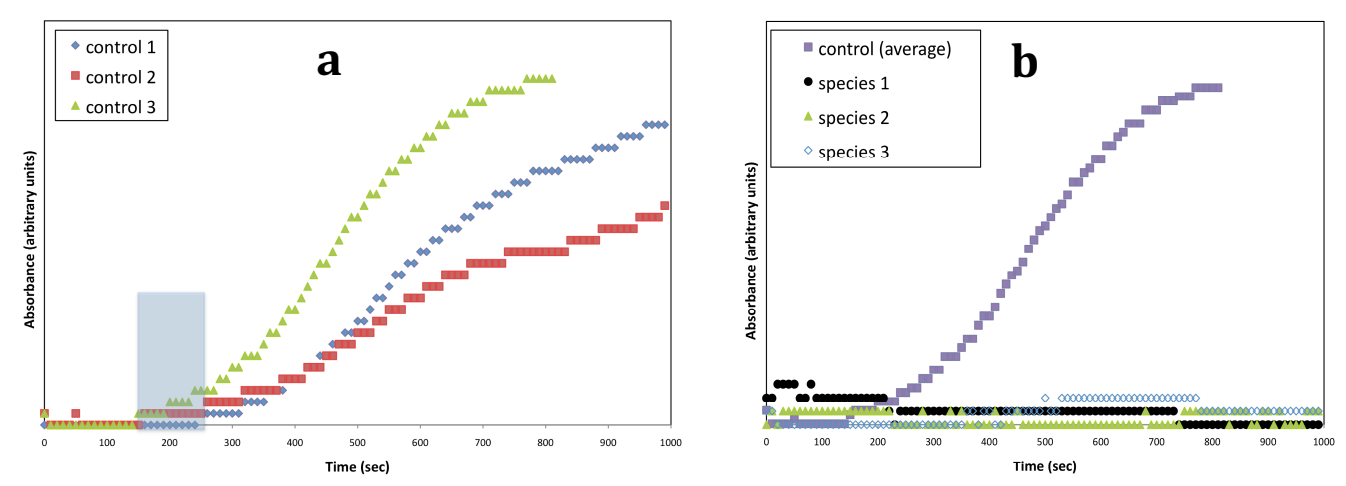

Figure 6. Absorbance at $900 \mathrm{~nm}$ versus time (a) reproducbility of method, greyed box shows variation in induction time measured (varied from $150-250 \mathrm{sec}$ ) in the presence of no additives and (b) with $500 \mathrm{ppm}$ of species $\mathbf{1}, 2$ and $\mathbf{3}$ present 

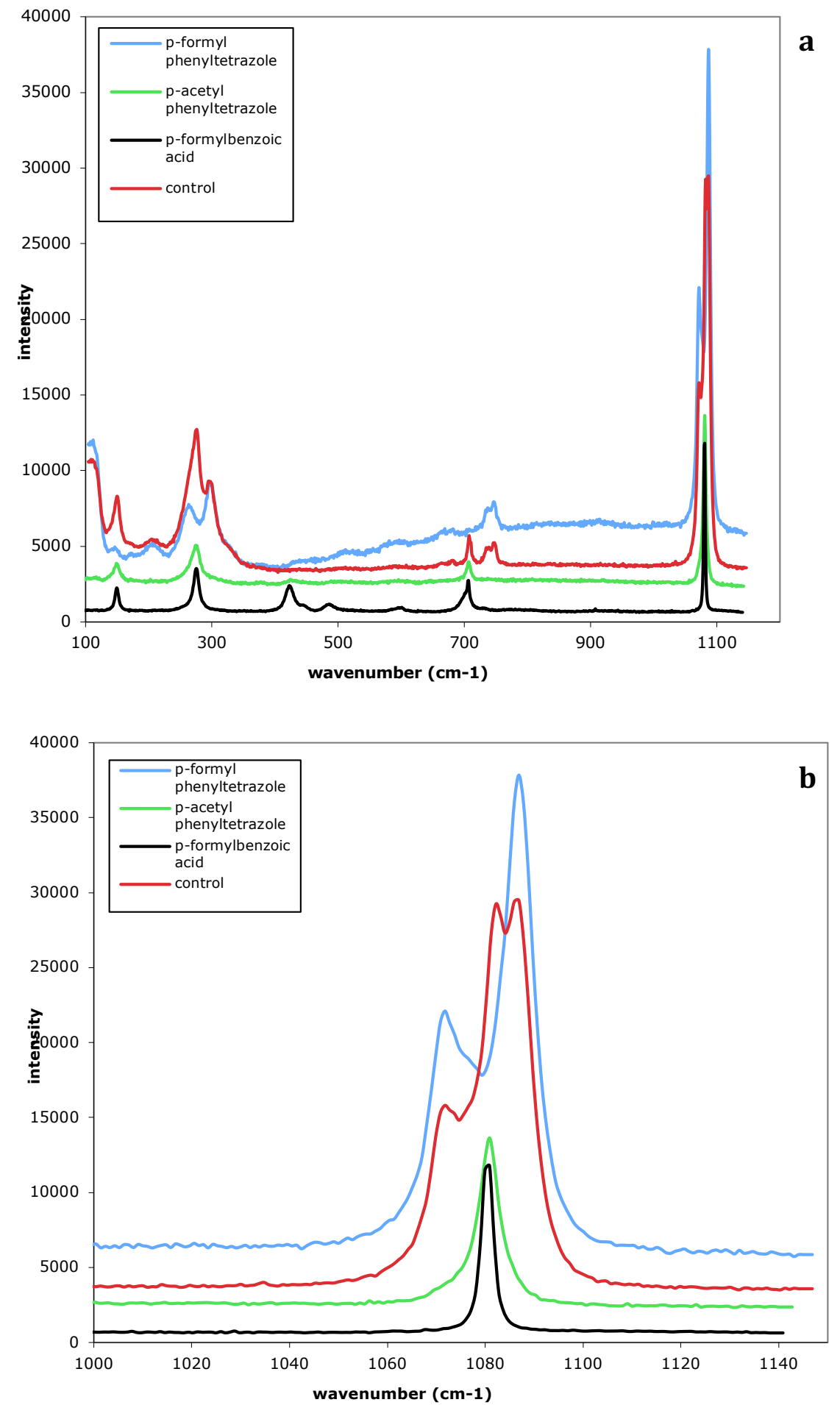

Figure 7. a) Raman spectra of calcium carbonate crystallized in the absence and presence of the additives. The $1080-1100 \mathrm{~cm}^{-1}$ region is shown in more detail in b) where the presence of calcite can be confirmed for the control and when additives $\mathbf{1}$ and $\mathbf{3}$ are present while vaterite is present in the control and in the presence of $\mathbf{2}$. 


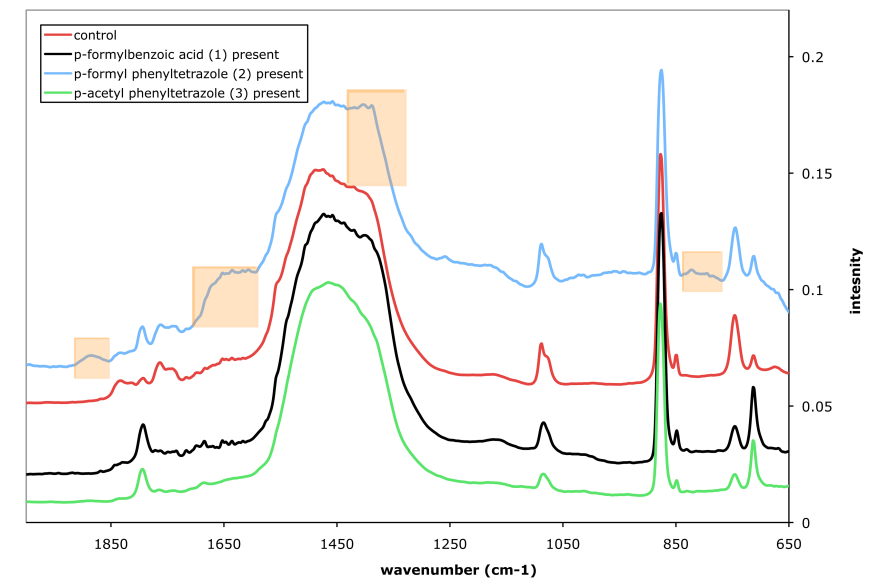

Figure 8. DRIFT spectra of calcium carbonate directly precipitated with and without additives present is shown. Differences in spectrum are highlighted by the rectangles when $\mathbf{2}$ is present. These peaks are from the tetrazole species (2) as confirmed by the solid state spectrum of $\mathbf{2}$ shown in the supplementary section (SFig. 4). 


\section{Supplementary Section}
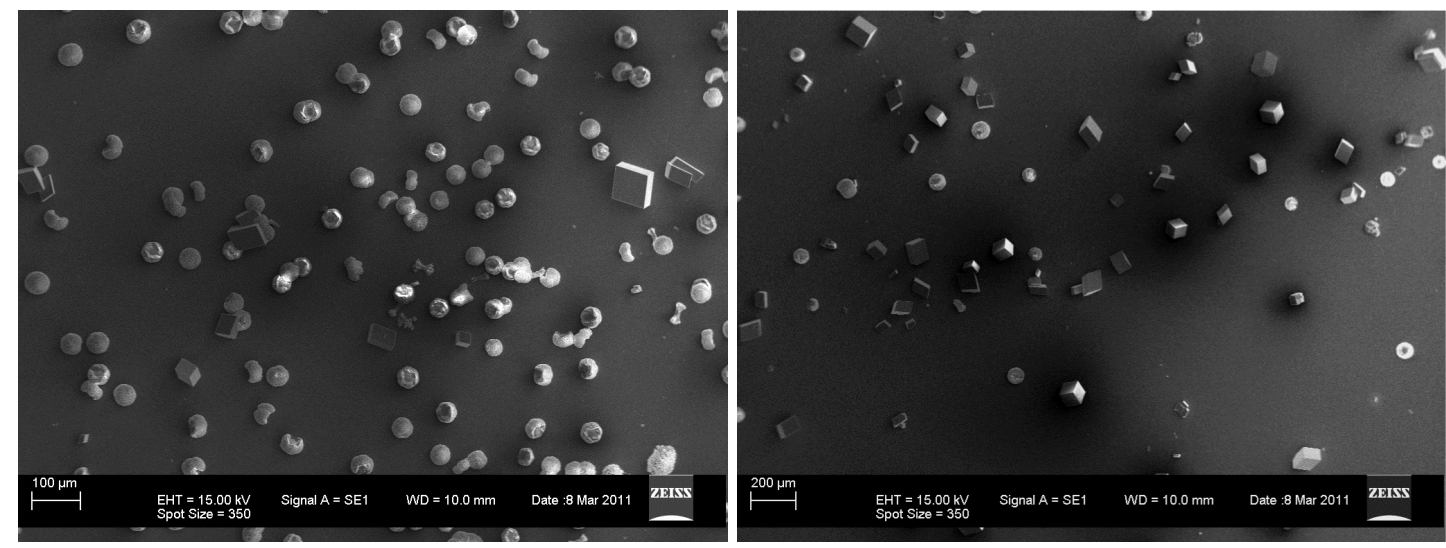

Calcium carbonate control after 7 days (scale bar is $100 \mu \mathrm{m}) 250 \mathrm{ppm}$

Calcium carbonate crystallization after 7 days in the presence of species 2 at $250 \mathrm{ppm}$ (scale bar is $200 \mu \mathrm{m})$

Calcium carbonate crystallization after 7 days with species 1 present (scale bar is $200 \mu \mathrm{m}$ )
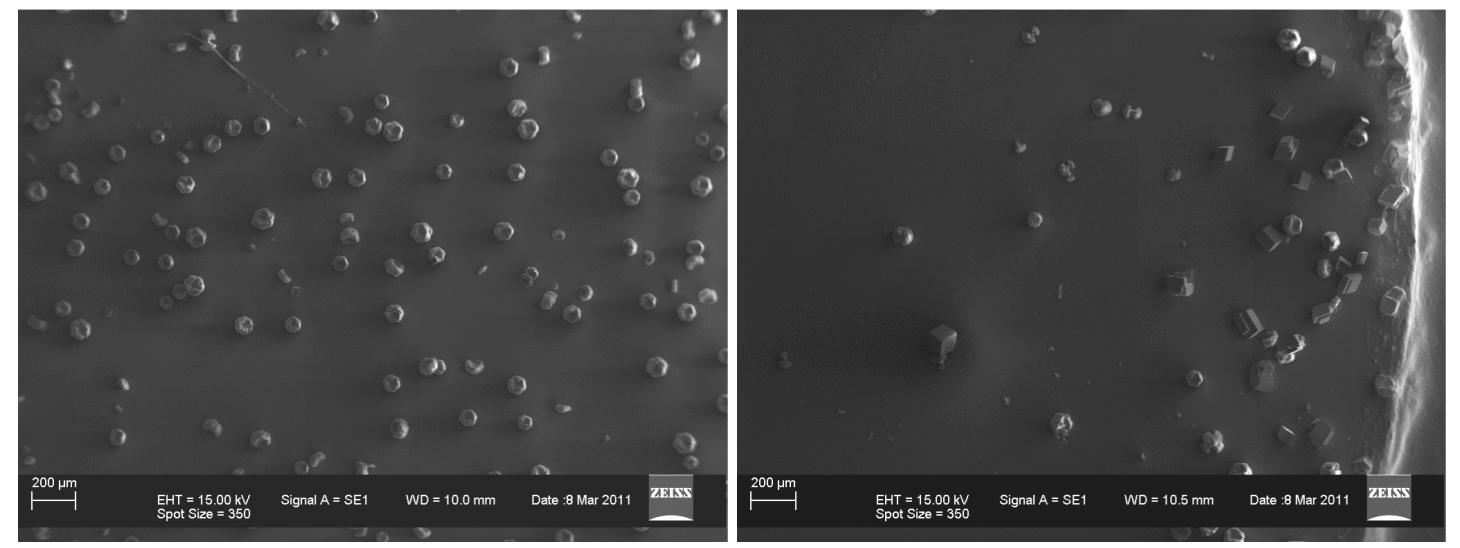

SFig.1. Lower magnification images of slow diffusion experiments

Calcium carbonate crystallization after 7 days with 250 ppm species 3 present (scale bar is 200 $\mu \mathrm{m})$ 


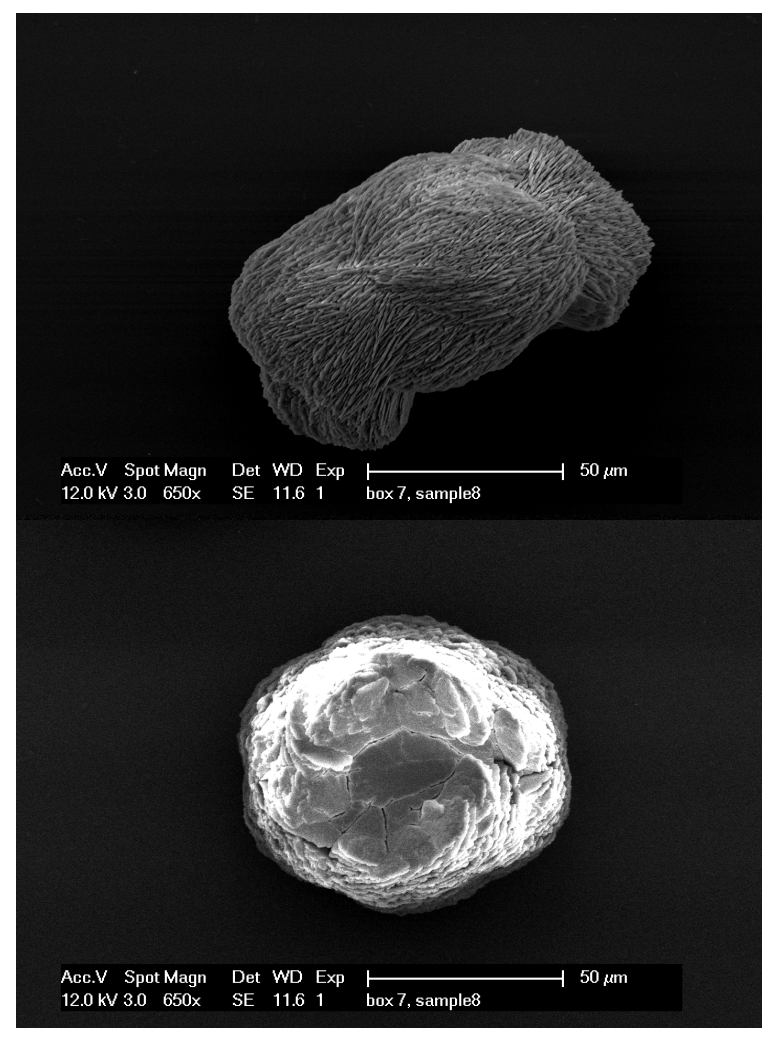

SFig 2. a) and b) SEM images of vaterite crystals after 14 days in the presence of 2

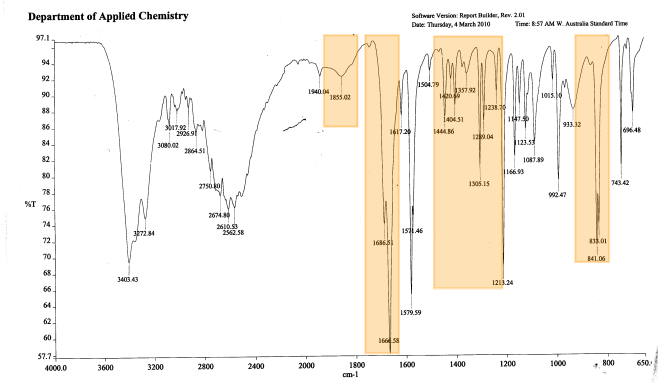

SFig. 3. Infrared spectrum of 4-(1H-tetrazol-5-yl)benzaldehyde (species 2) with highlighted regions that were observed adsorbed onto calcium carbonate in the DRIFT spectrum. NOTE: solid state spectrum has been obtained in transmission mode while calcium carbonate spectra have been obtained in absorbance mode. 